\title{
HOW DO ENGINEERING STUDENTS REACT TO MEMORIZATION VS. PROBLEM ANALYSIS QUESTIONS ON EXAMS?
}

\author{
Sarah DeDecker*, Ryan Clemmer, Karen Gordon, and Julie Vale \\ School of Engineering, University of Guelph \\ *sdedecke@uoguelph.ca
}

\begin{abstract}
In engineering, problem analysis skill development is an important aspect of student learning. This skill development may be hindered by the use of surface learning approaches to obtain adequate performance on assessments. In this study, two focus groups were used to investigate reactions to memorization and problem analysis questions on engineering exams based on the nature of the course.

Students are primarily motivated by grades and adopt a study approach that will allow them to achieve a high grade on a midterm exam based on the context of the course and contributing factors. When students are presented with memorization questions on an exam, they are more concerned with remembering the answer instead of using their knowledge base to solve the problem. When students perceive an exam will assess their problem analysis skills, they identified questions they have already seen before to be an unfair way to assess those skills. These results suggest that students employ different study approaches depending on the nature of the course and associated assessments. Therefore, exams should be designed with intent based on whether the instructor wants to assess their knowledge base or problem analysis skills.
\end{abstract}

Keywords: Problem analysis, Memorization, Student perception, Student study approach, Assessment fairness.

\section{INTRODUCTION}

Memorization is considered a surface approach to learning that involves regurgitating facts and reproduction of course material [1]. While memorization can be valuable, purely memorized knowledge on its own is insufficient when solving problems. Problem analysis (PA) integrates knowledge acquisition and application, and a defining feature of problem analysis is rooted in the unfamiliarity of the situation [2]. Engineering undergraduate students require strong problem analysis skills to analyze and solve real-world problems; this ability has been identified as an essential graduate attribute for these students [3], [4]. Previous research [5] has shown that engineering undergraduate students are employing surface approaches instead of PA skill development as a means of obtaining adequate performance on assessments, particularly when faced with time constraints. Using surface approaches to learning could lead to students relying on memorization to complete their assessments rather than fostering PA skills. Indeed, some research shows that engineering students tend to rely on memorization as a study approach compared to other disciplines [6].

There are three approaches to learning that students might take when meeting their learning goals for an assessment: surface, deep, or strategic [7]. Students may use a surface approach to learning when they intend to reproduce the course content. This learning approach is focused on memorizing and rehearsing information. Students may use a deep learning approach when they intend to understand the subject matter. Employing a deep approach involves comprehending the information, forming new ideas, and using evidence to refine prior knowledge. A deep learning approach is important because students tend to retain, integrate and transfer information at higher rates, and tend to associate deep learning approaches with a more enjoyable learning experience [6]. Finally, students may use a strategic approach when wanting to achieve a high grade on an assessment within the available time [7]. Students focus on managing their time, efforts and organize how they study. Combining strategic learning with deep learning approaches may help to improve students' study success [7].

Assessments drive student learning, and therefore impact how students prepare and participate in a course and the course assessments [7]. Previous research [8] identified students' perceptions of assessment quality to consist of six variables: 1) authenticity of assessment, 2) conditions of assessment, 3) credibility of assessment, 4) effects of assessment on student learning, 5) fairness of assessment, and 6) interpretation of test scores. Indeed, when investigating engineering undergraduate students' perceptions of assessments, a previous study found that the majority of participants believe at least half of an exam should contain questions that are similar to 
assignment questions or sample problems, and surface approach learners tend to perceive exams as unfair when too many questions are unfamiliar [5].

Instructors can foster meaningful learning by constructively aligning teaching methods and course assessments with the desired learning outcomes. Even though there are guidelines for developing effective assessments (e.g., exams), there is often discrepancy in the nature of the assessment and how the assessment aligns with the goal of developing higher cognitive levels of understanding within students [9]. Learning expectations are not always clearly communicated to students, which can cause a lack of transparency in what students are expected to learn and how students demonstrate this learning [10]. Student perceptions of assessment fairness can then be impacted by the lack of communication on assessment design and alignment [11]. Assessments should be designed to encourage students to take a deep learning approach, while developing higher cognitive learning skills (e.g., problem analysis skills) [12].

A preferred study method for science, technology, engineering, and mathematics (STEM) undergraduate students is re-reading lecture notes and the textbook, even though practice problems show more success in effective studying [13]. Re-reading and rehearsing information should not be applied mindlessly, and this method should not be used as a substitution for understanding material at a deeper level [14]. Therefore, students may be using ineffective study habits based on the nature of the course material and the course assessments (e.g., memorization versus PA course). Students who perceive the use of assessments in a course as a means to measure or quantify memorized knowledge become biased towards adopting a surface approach to learning and studying [1], [15]. Students adopt a deeper learning approach when they perceive the assessment will assess their understanding of the content instead of their memorization of the information [1].

The nature of an exam (e.g., open-book, closed-book, etc.) can also impact students' study approach. Students that use a surface approach to learning may reduce preparation for an open-book exam. Using a surface approach can lead to students devoting considerable amounts of time during the exam locating the information they need from the reference material (e.g., course textbook, course notes, formula sheet, etc.) to solve problems and having less time to formulate their answers [16]. Students who employ a deep approach when studying will learn how to organize and apply the course material before the open-book exam and learn how to use their acquired knowledge to solve problems [17]. Formula sheets can be used as a study aid, but it appears that the time students spend on studying for an exam potentially has a higher impact on performance than whether the students are given reference material or not during the exam [18].

Given the role that assessment design plays in driving student-learning approaches, this study aims to investigate reactions to engineering exam questions based on the nature of the course. The research question posed in this work is:

- How do engineering students react to memorization vs. problem analysis questions on exams?

To assist in answering this question, two focus groups were conducted with engineering undergraduate students at the authors' home institution.

\section{METHODOLOGY}

Recruitment for focus groups was administered via email to undergraduate engineering students enrolled in two core engineering courses (enrolment for Course 1 was 179 students and enrolment for Course 2 was 126 students). The focus groups were part of another student study involving an assessment framework [19]. The University's Research Ethics Board approved this study and students gave informed consent to participate in the focus groups. Focus groups were conducted for two courses during the Winter 2019 semester: Course $1(n=5)$ and Course $2(n=4)$. Course 1 is a mandatory course delivered to seven engineering programs and Course 2 is mandatory for six engineering programs. The authors of this paper conducted the focus groups and were not the instructors of the two courses investigated in this study.

\subsection{Courses}

Course 1 was a traditional offering of a second year course, which included the following assessments: ungraded assignments, laboratory reports, course related project, midterm exam, and final exam. The course had three hours of lectures and two hours of laboratory sessions per week. The nature of Course 1 was identified based on graduate attributes, which have been established by the Canadian Engineering Accreditation Board [4]. Students demonstrated knowledge base of engineering in Course 1 by recalling and describing engineering principles. Therefore, Course 1 was identified as a knowledge heavy course by the graduate attributes curriculum improvement process, the instructor and focus group students. The large volume of course content tends to make this course a memorization-based course.

Course 2 was a traditional offering of a third year course, which included the following assessments: ungraded assignments, tutorial quizzes, lab reports, midterm exam, and final exam. The course had three hours of lectures per week and two hours for each problem analysis tutorial and laboratory session. Students demonstrated problem analysis of engineering in Course 2 by applying knowledge and skills to identify, formulate, 
analyze, and solve engineering problems. Therefore, Course 2 was identified as a PA course by the graduate attributes curriculum improvement process, the instructor and focus group students.

\subsection{Exams}

Students created their own double-sided formula sheet to use during the midterm exam for Course 1. Steps for solving problems or numerical solutions were not allowed on the formula sheet. The exam for Course 1 was 70 minutes in length. The midterm exam for Course 2 was open book, but students were only allowed to use the textbook (no course notes or problem solutions) during the exam. The exam for Course 2 was 120 minutes. The course instructors designed the exams and there was no intentional instruction or guidance on the design of the exams from the authors of this paper.

An assessment framework [19] was used to identify one memorization and one PA question on each course midterm exam. The memorization questions provided all the data needed to solve the problem and were similar questions to course practice problems. The PA questions had many concepts and a specific approach to solving the problem was not given to the students.

\subsection{Focus Groups}

After the midterm exams, students volunteered to participate in a 60-minute focus group (Course 1: 2 females and 3 males; Course 2: 1 female and 3 males). Students received 30 minutes of training on how to use an assessment framework, but scoring results from that aspect of the focus groups are not included in this paper. Within that thirty-minute training, students reflected on memorization and the role of memorization in learning. Students were then asked open-ended questions that prompted student reflection on their reactions to the midterm exam questions. Some of the semi-structured interview questions asked during the focus groups were:

1. What was your overall motivation to learn and study the course material?

2. How did you go about studying and preparing for the midterm?

3. How would you characterize this course? Is it a memorization based course or a problem analysis course?

4. After writing the midterm exam, will you change your study approach moving forward in this course?

5. Briefly describe what makes a fair exam and was this course exam fair?

The researchers reviewed the focus group transcripts and qualitatively identified key themes and obtained insights from the students' responses.

\section{RESULTS}

Key themes were identified based on the questions asked during the focus groups. The key themes from the transcripts were: student motivation, exam study approach, and exam fairness. Quotes directly from the students have been used to encourage richness and authenticity in the presentation of the focus group results.

\subsection{Student Motivation}

Students were asked about their motivation to study for their midterm exam. The majority of focus group participants were motivated primarily by grades and wanting to pass the midterm exam. Participants also identified secondary motivating factors such as wanting to learn the course content and apply it to real world problems:

"Specifically preparing for exams, I would say grades are my primary motivation, but more generally, my motivation to learn a course, to apply myself within the course, is to understand those concepts as they can be applied to real world problems."

One participant was also motivated by co-op placements and these real world experiences guided their motivation to learn so they can apply their knowledge and skills outside of the classroom,

"Having windows of co-op helps to realign my goals, like I'll get an idea of what people who are in the field working, what they know and what knowledge and skills they apply and use that to direct my own learning."

\subsection{Exam Study Approach}

Students were asked what approach they took when studying for their midterm exam. Participants identified different study approaches when enrolled in the memorization course versus the PA course. Students who were enrolled in the memorization course studied from the lecture notes and did not complete the practice problems. They created study notes and a formula sheet based on content presented in the lecture notes because they reported that they did not find the practice problems useful. Students used the practice problems only for the purpose of anticipating what types of questions they could expect on the exam. For example,

"I didn't really answer the questions, I was just looking over them and seeing how I may go about it and look at the solution and then build an understanding of what the questions require me to do."

Since students identified this course as a memorizationbased course they felt more inclined to spend their study time ensuring they knew the knowledge based content from the lecture notes instead of developing their PA skills by working through practice problems,

"This course is kind of different than other engineering courses, where it has actual written content that we need to know how to apply, not just solving problem, so I actually tried to kind of memorize some things." 
Another student in the memorization course felt unprepared for the PA question on the midterm exam because their study approach focused more on learning course-based knowledge, instead of application of that knowledge in a problem setting.

One student mentioned that they felt "lucky" that they had incorporated the information needed to solve one of the exam questions on their formula sheet,

"I had a lot of stuff on my sheet that did help me with this question, which is kind of lucky I guess because when I was looking at the slides I thought maybe this would be useful."

A student identified that they planned to change their study approach for the final exam in Course 1,

"I think I'm going to leave some time for the problem sets because I didn't really do those and I know there was a question similar to this in the problem set because someone told me."

Students who were enrolled in the PA course took a different approach to studying. These participants mentioned that they worked through the practice problems as a way to study for the exam, and if they were unclear on how to solve the problem, then they would refer back to the lecture notes. For example,

"I generally go through the problem sets and then if I have any questions with the problem, I'll refer back to the lecture to see if I missed any concepts."

Contributing external factors were also identified as playing a role in how the students approached studying for the exams. Focus group participants identified that they had to alter their study approach (study strategically) to accommodate for time constraints and other midterms during this time period:

"Prior to exams you can get caught up in trying to know everything and then you don't have enough time to actually do all of the exam prep. It's a different approach."

Another student mentioned, "I was scared I was going to fail \{another course\}, so that's why \{Course 1\} was put on the back burner a little bit. I only had one day to study for \{Course 1\}, which wasn't smart."

\subsection{Exam Fairness}

When discussing the identified memorization questions, particularly questions similar to the problem sets, students indicated that they were more concerned with remembering the answer than with using knowledge base to solve the problem,

"You might be doing the right thing but you second guess because it's not what you expected \{the answer\} to be from what you've seen before."
Alternatively, when reflecting on PA questions, students recognized the need to use their knowledge base to interpret the problem. Moreover, students reported that so-called "easy" questions were contrary to encouraging student ownership of their learning,

"I don't like when we get questions that we've already seen on exams because I don't think it displays how you know how to do something. You're trying to remember \{the answer\} instead of looking at your answer and going do you think this is valid."

Students identified that questions they have seen before encourage memorization and does not focus on developing PA skills, which they identified is an important skill for engineers,

"It's important for you to be good at problem analyzing because that's what engineers do fundamentally. They analyze problems and try to solve them."

\section{DISCUSSION}

\subsection{Student Motivation}

This study provided insights about how some engineering undergraduate students are motivated to study for memorization and PA courses. When reflecting on both course types, the students' responses indicated that grades were the primary motivation to learn and study the course content. Previous studies have shown that grades are a factor that can impact academic motivation in students and can even create a fear of failure [20]. The motivation for the students in the current study was a combination of wanting to pass, managing their time around studying for other courses, and to learn the material to apply it later in their careers. Co-op placements and experiential learning opportunities drive student motivation because they provide students with real-world learning applications. Therefore, students tend to adopt a study approach that will allow them to achieve a high grade on an assessment (e.g., midterm exam) based on the context of the course, and external pressures.

\subsection{Exam Study Approach}

As previously mentioned, students may feel "lucky" if their self made formula sheet includes information they did not study but wrote down because they thought it could be useful or important. A formula sheet might encourage a student to adopt a memorization approach if they solely rely on that tool for answering problems and the student may memorize additional content they cannot fit on their formula sheet. Other students might create a formula sheet with the intent of using that as a studying aid and helping them engage in PA skill development by only using the sheet as a quick reference. The results from this study are inconclusive on how reference materials on 
exams impact student study approaches and warrant further investigation.

\subsection{Exam Fairness}

When students perceive that exams should include problems they have practiced in assignments and sample problems, they may consider the exam to be unfair when their skills are assessed through new, unseen problems [5]. However, to accurately assess students' PA skills, it is important to expose students to unfamiliar problems [3]. It becomes challenging for instructors to design assessments that assess students' PA skills without the students' perceiving the assessment to be extremely unfair. This study found when discussing exam fairness in a specific course, students felt it was unfair in a problem analysis course to give PA questions on the exam that they had already seen before. Students believed that their PA skills were not being assessed effectively. They believed that someone who took a memorization study approach and someone who took a PA study approach could do just as well on questions they had already seen before. Using previously seen questions and using similar questions may disadvantage deep learners, enable the memorizers, and decrease the discrimination of the assessment related to students' problem analysis abilities.

In the case of memorization questions, students indicate that when they are faced with a problem similar to one they have seen before, they are hesitant to rely on their problem solving skills, and instead revert to a memorization strategy. This is an interesting finding, and verifies that students will choose a strategy in responding to a question where they have the most confidence in obtaining the best grades.

One student questioned the purpose of the exam and whether the instructor wanted to test "students' knowledge or problem analysis skills," and communicating this objective with the students may alter students' perceptions of the assessment. An instructor's teaching style through in-class material and emphasis on concepts, and studying cues may also have consequences on the student's approach to studying [13]. If students are informed on the assessment design and learning expectations, then they may adopt a different study approach.

\subsection{Limitations}

Limitations of this exploratory study include that participants may be biased in this study because the focus groups were voluntary and students may have been motivated to participate based on an interest in the study's topic or ulterior motivates of interacting with faculty members within the engineering department. Given the small sample size of the focus groups, the participants' responses do not represent all engineering undergraduate students, but they do provide some insight into student perceptions of learning and assessment. The intent of this preliminary study was to identify themes that may serve as topics for future work. Participants ranged in year of study and some of them have co-op placements within their degree program, which means the maturity level of PA skills may have affected their responses. Students may have been reluctant to openly share their thoughts about exam questions and study habits in front of their peers causing social effects on the focus group results.

\subsection{Future Work}

The findings from this study will inform the development of an assessment framework [19] to aid in constructive alignment. This framework will help assessment design by aligning learning outcomes with assessment activities. Future work will study student perceptions on learning approaches and assessment design. One notable topic generated from this study is further investigation of the efficacy of study aids in promoting a deeper learning approach.

\section{CONCLUSIONS}

Students tend to leverage different study approaches depending on the nature of the course and associated assessments. Students in memorization-based courses tend to study course-based knowledge, which may foster surface approaches to learning. Students in problem analysis courses indicated the importance of working through practice problems and indicated that PA questions required students to apply their knowledge. Instructors should design their assessments (e.g., exams) with intent to assess knowledge base or problem analysis skills based on the learning outcomes of the course.

\section{References}

[1] Alf Lizzio, Keithia Wilson, and Roland Simons, "University Students' Perceptions of the Learning Environment and Academic Outcomes: Implications for Theory and Practice." Studies in Higher Education, vol. 27, no. 1, pp. 27-52, 2002.

[2] Samuel Greiff, et al. "Assessing Complex ProblemSolving Skills with Multiple Complex Systems." Thinking \& Reasoning, vol. 21 , no. 3, pp. 356-82, 2015.

[3] Donald R. Woods, "An Evidence-Based Strategy for Problem Solving." Journal of Engineering Education, vol. 89, no. 4, pp. 443-59, 2000.

[4] Canadian Engineering Accreditation Board, "A Guide to Outcomes-Based Criteria.” pp. 1-35, 2015.

[5] Ryan Clemmer, Karen Gordon, and Julie Vale, "Will That Be on the Exam? - Student Perceptions of Memorization and Success in Engineering." Proceedings of the Canadian Engineering Education Association (CEEA), 2018. 
[6] Thomas F. N. Laird, Rick Shoup, and George D. Kuh, "Deep Learning and College Outcomes: Do Fields of Study Differ?" Annual meeting of the Association for Institutional Research, 2005.

[7] Karin J. Gerritsen-van Leeuwenkamp, Desirée Joosten-ten Brinke, and Liesbeth Kester, "Students' Perceptions of Assessment Quality Related to Their Learning Approaches and Learning Outcomes," Studies in Educational Evaluation, vol. 63, pp. 72-82, 2019.

[8] Karin J. Gerritsen-van Leeuwenkamp, Desirée Joosten-ten Brinke, and Liesbeth Kester, "Developing Questionnaires to Measure Students' Expectations and Perceptions of Assessment Quality." Cogent Education, vol. 5, no. 1, pp. 1-16, 2018.

[9] John Biggs, "Enhancing Teaching Through Constructive Alignment." Higher Education, vol. 32, no. 3, pp. 347-364, 1996.

[10] Helen Larkin and Ben Richardson, "Creating High Challenge/High Support Academic Environments through Constructive Alignment: Student Outcomes." Teaching in Higher Education, vol. 18, no. 2, pp. 192204, 2013.

[11] John Biggs, "Constructive Alignment in University Teaching." HERDSA Review of Higher Education, vol. 1, pp. 5-22, 2014.

[12] Paul Ramsden, Learning to Teach in Higher Education. London, UK: Routledge, 2003 ( $2^{\text {nd }}$ ed.), 288 pp. \{ISBN: 978-0203-50771-1\}

[13] Matthew T. Hora and Amanda K. Oleson, "Examining Study Habits in Undergraduate STEM Courses from a Situative Perspective." International Journal of STEM Education, vol. 4, no. 1, pp. 1-19, 2017.

[14] Harry N. Blumner and Herbert C. Richards, "Study Habits and Academic Achievement of Engineering Students." Journal of Engineering Education, vol. 86, no. 2, pp. 125-32, 1997.

[15] Siobhan Lynam and Moira Cachia, "Students' Perceptions of the Role of Assessments at Higher Education." Assessment \& Evaluation in Higher Education, vol. 43, no. 2, pp. 223-34, 2018.

[16] Christos Theophilides and Omiros Dionysiou, "The Major Functions of the Open-Book Examination at the University Level: A Factor Analytic Study." Studies in Educational Evaluation, vol. 22, no. 2, pp. 157-70, 1996.

[17] Christos Theophilides and Mary Koutselini, "Study Behavior in the Closed-Book and the Open-Book Examination: A Comparative Analysis." Educational Research and Evaluation, vol. 6, no. 4, pp. 379-93, 2000.

[18] Marc J. Sanborn, Kathryn T. Purchase, and Brook E. Barry, "Kicking out the Crutch: The Impact of Formula Sheets on Student Performance and
Learning." ASEE Annual Conference and Exposition, Conference Proceedings, 2012.

[19] Ryan Clemmer, Karen Gordon, and Julie Vale, "The Problem Analysis and Memorization Diagnostic: A Tool to Discourage Memorization through Assessments." STLHE 2019 Conference, Winnipeg, MB, 2019.

[20] Kelsey Chamberlin, Maï Yasué, and I-Chant Andrea Chain, "The Impact of Grades on Student Motivation." Active Learning in Higher Education, pp. 1-16, 2018. 